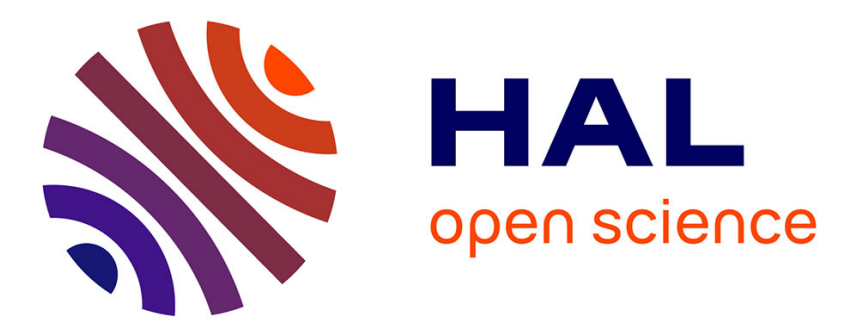

\title{
Effect of Phosphorus on Hot Ductility of High Purity Iron
}

\author{
K. Abiko, C.-M. Liu, M. Ichikawa, H. Suenaga, M. Tanino
}

\section{To cite this version:}

K. Abiko, C.-M. Liu, M. Ichikawa, H. Suenaga, M. Tanino. Effect of Phosphorus on Hot Ductility of High Purity Iron. Journal de Physique IV Proceedings, 1995, 05 (C7), pp.C7-335-C7-340. 10.1051/jp4:1995740 . jpa-00254034

\section{HAL Id: jpa-00254034 https://hal.science/jpa-00254034}

Submitted on 1 Jan 1995

HAL is a multi-disciplinary open access archive for the deposit and dissemination of scientific research documents, whether they are published or not. The documents may come from teaching and research institutions in France or abroad, or from public or private research centers.
L'archive ouverte pluridisciplinaire HAL, est destinée au dépôt et à la diffusion de documents scientifiques de niveau recherche, publiés ou non, émanant des établissements d'enseignement et de recherche français ou étrangers, des laboratoires publics ou privés. 


\title{
Effect of Phosphorus on Hot Ductility of High Purity Iron
}

\author{
K. Abiko, C.-M. Liu, M. Ichikawa*, H. Suenaga and M. Tanino \\ Institute for Materials Research, Tohoku University, Sendai 980-77, Japan \\ * Graduate School of Engineering, Tohoku University, Sendai 980-77, Japan
}

\begin{abstract}
Tensile tests on high purity $\mathrm{Fe}-\mathrm{P}$ alloys with $0,0.05$ and 0.1 mass $\% \mathrm{P}$ were carried out at temperatures between $300 \mathrm{~K}$ and $1073 \mathrm{~K}$ to clarify the intrinsic effect of phosphorus on the mechanical properties of iron at elevated temperatures. Microstructures of as-quenched, interrupted and ruptured specimens were observed. Experimental results show that the addition of phosphorus causes a remarkable increase in proof stress of high purity iron at $300 \mathrm{~K}$, but the increase in proof stress by phosphorus decreases with increasing test temperature. The strengthening effect of phosphorus reduces to zero at $1073 \mathrm{~K}$. High purity iron and Fe-P alloys rupture at almost $100 \%$ reduction in area at the whole test temperatures. However, Fe-P alloys show much larger elongation at test temperatures above $773 \mathrm{~K}$ than high purity iron. The increased elongation of high purity iron by addition of phosphorus was shown to be related to the effect of phosphorus on dynamic recovery and recrystallization of iron as its intrinsic effect.
\end{abstract}

\section{INTRODUCTION}

Phosphorus is one of the typical harmful impurities in iron and steels which causes intergranular fracture (IGF) at low temperatures by segregation at grain boundaries [1,2]. On the other hand, it causes considerable solid solution hardening and improves the ductility of iron and some steels at elevated temperatures. Kirby and Beevers [3] clarified the effect of $0.14 \%$ phosphorus on the creep behaviour of $\alpha$ iron. They reported that the addition of phosphorus to iron suppresses the nucleation of cavities at grain boundaries and increases the elongation of iron at high creep temperatures. The suppression of cavity nucleation in $0.14 \% \mathrm{P}$ alloy has been attributed to the lowering of the grain boundary energy of $\alpha$-iron by the addition of phosphorus. Abiko et al $[4,5]$ found that the addition of phosphorus increases creep ductility of 2.25Cr-1Mo steel. Pope and his co-workers [6-9] also reported that the addition of phosphorus to low alloy steels improves the creep ductility and the tensile ductility at elevated temperatures. They considered that the role of phosphorus is to slow cavity growth by reducing the grain boundary diffusion rate of iron and/or by competing with sulphur on the free surfaces. Recently, some researchers have investigated the effects of phosphorus on the creep cavitation and high temperature ductility of Fe-S alloys [10-13]. The results clearly showed that the addition of phosphorus to $\mathrm{Fe}-\mathrm{S}$ alloys improves high temperature ductility by reducing intergranular cavitation caused by sulphur. The reduction of intergranular cavitation in Fe-S alloys by phosphorus has been shown to be caused by the displacement of sulphur from grain boundaries by phosphorus [13].

However, the effects of phosphorus reported so far do not appear to be common because no cavitation was observed in high purity iron at tensile test temperatures up to $1173 \mathrm{~K}$ [14], whereas intergranular cavitation always occurred in the phosphorus-undoped samples in the previous studies [3-13]. Therefore, 
the intrinsic effect of phosphorus on the hot ductility of iron is still unclear. The purpose of the present study is to clarify the intrinsic effect of phosphorus using high purity iron samples.

\section{EXPERIMENTAL PROCEDURES}

The high purity Fe-P alloys were made from high purity electrolytic iron and specially prepared high purity Fe-P mother alloy (about 16 mass $\%$ P) by melting in a high vacuum induction furnace. High purity alumina crucibles lined with calcia were used for melting. The melt iron was deoxidized with high purity Fe-4.7\% mother alloy. The ingots were hot forged and hot rolled to round rods of $12 \mathrm{~mm}$ diameter, and cold rolled to round rods of $6.5 \mathrm{~mm}$ in diameter, with adequate precautions to avoid contamination. Tensile test specimens of $20 \mathrm{~mm}$ gauge length and $3 \mathrm{~mm}$ diameter were machined from the round rods of $6.5 \mathrm{~mm}$ diameter. Table 1 shows the results of the chemical analysis of the alloys.

Every specimen was annealed at $973 \mathrm{~K}$ in flowing wet and dry purified hydrogen gas, for 24 hours each, to remove as much carbon as possible. The concentration of residual carbon after the hydrogen treatment was chemically analyzed as shown in Table 1 . The concentration of carbon in the alloys had been reduced to the limit detectable by chemical analysis ( 1 mass ppm). Then, the specimens were heated for 15 minutes at $1133 \mathrm{~K}$ for $\mathrm{Fe}, 1123 \mathrm{~K}$ for $\mathrm{Fe}-0.05 \mathrm{P}$ and $1073 \mathrm{~K}$ for $\mathrm{Fe}-0.1 \mathrm{P}$ under a vacuum of $1.3 \times 10^{-2} \mathrm{~Pa}$ to obtain the average grain size of $200 \mu \mathrm{m}$. Finally, every specimen was kept for 1 hour at $1073 \mathrm{~K}$ and quenched in an oil bath at $273 \mathrm{~K}$ without breaking the vacuum to control the same microstructure condition.

The tensile tests were carried out at temperatures between $300 \mathrm{~K}$ and $1073 \mathrm{~K}$ in a high vacuum of $3.8 \times 10^{-4} \mathrm{~Pa}$. A strain rate of $4.2 \times 10^{-5 / \mathrm{s}}$ was mainly used. The microstructures of specimens as quenched, interrupted after deformation to a given strain and ruptured were observed by Normarski-type differential interferometric optical microscopy.

Table 1: Chemical analysis results of the alloys

\begin{tabular}{|c|c|c|c|c|c|c|c|c|c|c|c|c|c|}
\hline & mass\% & \multicolumn{12}{|c|}{ mass ppm } \\
\hline & $\mathrm{P}$ & $\mathrm{S}$ & $\mathrm{O}$ & $N$ & $\mathrm{~B}$ & Mo & $\mathrm{Cr}$ & $\mathrm{Mn}$ & $\mathrm{Ni}$ & $\mathrm{Si}$ & $\mathrm{Al}$ & $C$ & $\mathrm{C}^{* *}$ \\
\hline $\mathrm{Fe}$ & 0.0003 & 1.6 & 5 & $<4$ & 0.9 & $<1$ & $<1$ & $<1$ & $<1$ & 1 & 1 & 76 & 0.8 \\
\hline $\mathrm{Fe}-0.05 \mathrm{P}$ & 0.050 & 1 & 11 & $<4$ & 1.6 & $<1$ & $<1$ & $<1$ & $<1$ & 1 & 2 & 113 & 1.1 \\
\hline $\mathrm{Fe}-0.1 \mathrm{P}$ & 0.10 & 1 & 10 & $<4$ & 1.8 & $<1$ & $<1$ & $<1$ & $<1$ & 1 & 1 & 109 & 1.3 \\
\hline
\end{tabular}

$\mathrm{C}^{*}$ : The concentration of carbon after hydrogen treatment

\section{RESULTS}

\subsection{Tensile tests}

Every specimen of high purity iron and Fe-P alloys with 0.05 and $0.1 \%$ P ruptured at almost $100 \%$ reduction in area at the test temperatures between $300 \mathrm{~K}$ and $1073 \mathrm{~K}$. Therefore, the effect of phosphorus on the hot ductility of iron was evaluated by the elongation to rupture.

Figure 1 shows the relationship between elongation to rupture and test temperature. At test temperatures below $723 \mathrm{~K}$, there is no definite difference in elongation between high purity iron and Fe-P alloys. A slight drop of elongation was observed in high purity iron and Fe-P alloys at $573 \mathrm{~K}$, which results from the interaction between dislocation and the trace of carbon or nitrogen in solid solution. On the other hand, at test temperatures above $773 \mathrm{~K}$, the elongation of Fe-P alloys becomes much greater than that of high purity iron in spite of the great elongation variation in Fe-P alloys. Clearly, phosphorus remarkably increases the hot ductility of iron. In this test temperature range, the elongation of high purity iron slightly increases with test temperature, whereas there appears to be no clear dependence on elongation on test temperature in Fe-P alloys. 
The effect of phosphorus on strength was evaluated by $0.1 \%$ proof stress since no yielding was observed for high purity iron and Fe-P alloys at the test temperatures, except the test at $300 \mathrm{~K}$ for Fe-P alloys. Figure 2 shows the proof stress of high purity iron and Fe-P alloys against the test temperature. Addition of phosphorus to high purity iron causes a remarkable increase in proof stress at $300 \mathrm{~K}$. The increase in proof stress by phosphorus decreases with increasing test temperature. The strengthening effect of phosphorus reduces to zero at $1073 \mathrm{~K}$. It should be noted that the proof stress of Fe-0.1P alloy between $723 \mathrm{~K}$ and $773 \mathrm{~K}$ increases slightly with test temperature. However, no increase in the proof stress of high purity iron is observed in this temperature range.

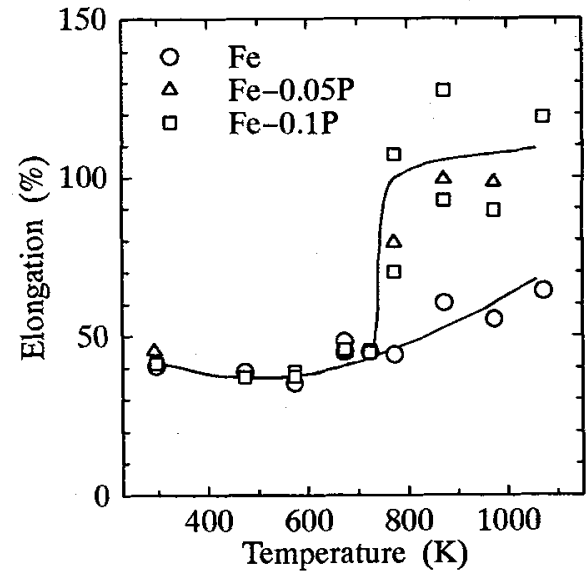

Figure 1: Relationship between elongation and test temperature for high purity iron, $\mathrm{Fe}-0.05 \mathrm{P}$ and $\mathrm{Fe}-0.1 \mathrm{P}$ alloys.

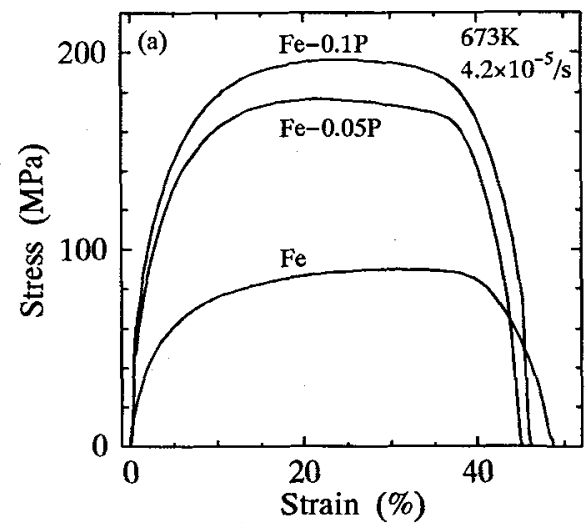

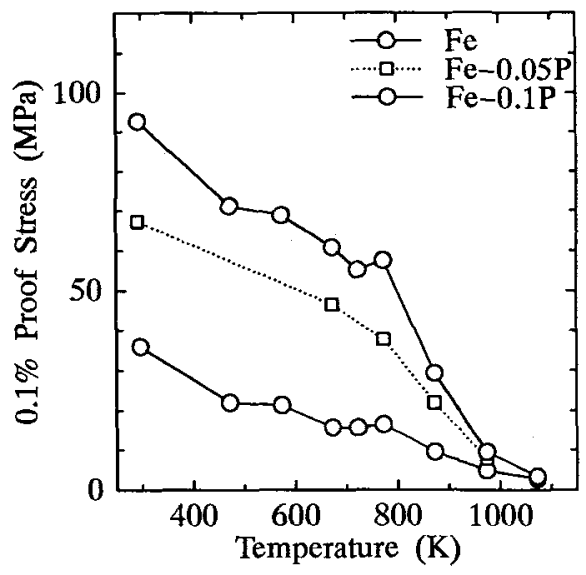

Figure 2: The $0.1 \%$ proof stress of high purity iron and Fe-P alloys against the test temperature.

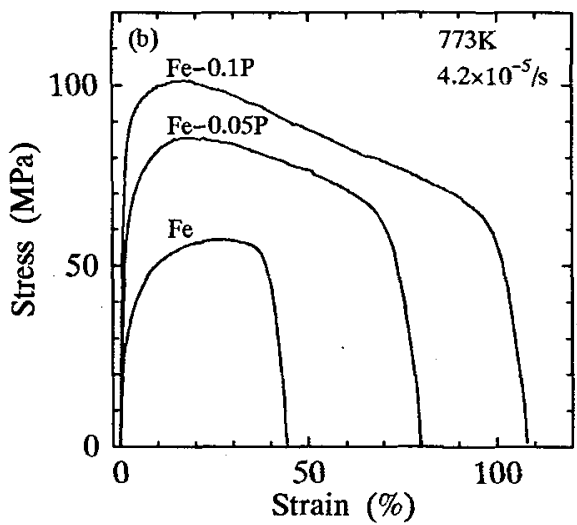

Figure 3: Stress-strain curves of high purity iron and Fe-P alloys at $673 \mathrm{~K}$ (a) and $773 \mathrm{~K}$ (b).

Figure 3 shows the stress-strain curves of high purity iron and Fe-P alloys at $673 \mathrm{~K}$ (a) and $773 \mathrm{~K}$ (b). The stress-strain curves at $673 \mathrm{~K}$ and at $773 \mathrm{~K}$ are representative of those at temperatures below $723 \mathrm{~K}$ and above $773 \mathrm{~K}$, respectively. At $673 \mathrm{~K}$, although Fe-P alloys shows greater work hardening than high purity iron, their stress-strain curves are similar to each other. The flow stresses drop rapidly by necking after maximum flow stress. On the other hand, the stress-strain curve of high purity iron at $773 \mathrm{~K}$ is similar to that of high purity iron at $673 \mathrm{~K}$. In contrast, the flow stresses of Fe-P alloys at $773 \mathrm{~K}$ fall slowly without necking after reaching a maximum rapidly. 


\subsection{Microstructure observations}

The microstructures of as-quenched high purity iron and Fe-P alloys consist of equiaxial $\alpha$-phase with an average grain size of $200 \mu \mathrm{m}$. As described in the above section, the effect of phosphorus on the hot ductility of iron below $723 \mathrm{~K}$ is remarkably different from that above $723 \mathrm{~K}$. Microstructures of interrupted and ruptured specimens were observed for the specimens tested at temperatures below and above $773 \mathrm{~K}$. The microstructures were observed along the uniformly deformed cross section parallel to the tensile axis.

Figure 4 shows the optical microstructures of a high purity iron (a) and an Fe-0.05P alloy (b) ruptured at $673 \mathrm{~K}$. The number of slip lines in Fe-0.05P alloy is greater than that in high purity iron. No recrystallized grains were observed either in high purity iron or in Fe-0.05P alloy.

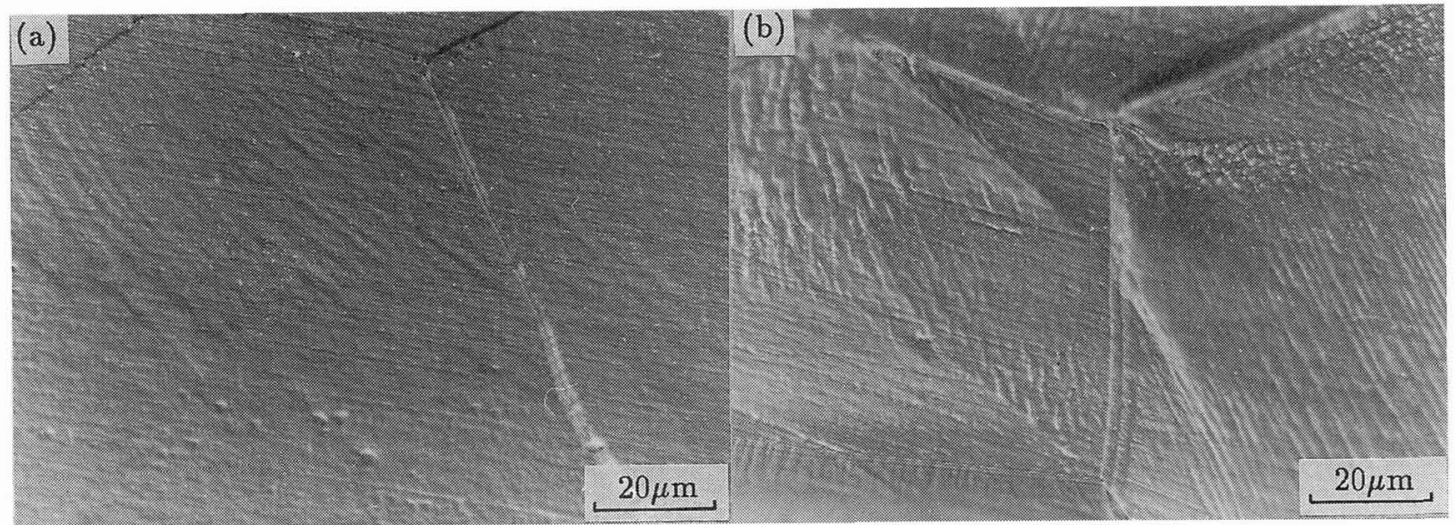

Figure 4: The optical microstructures for a high purity iron (a) and an Fe-0.05P alloy (b) ruptured at $673 \mathrm{~K}$.

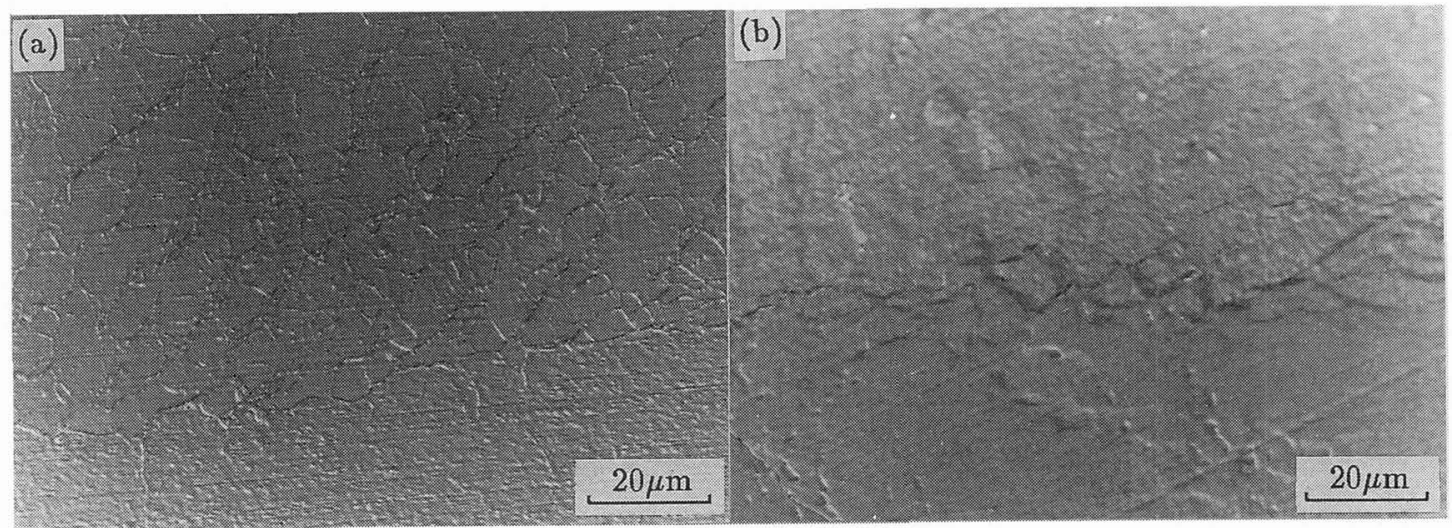

Figure 5: The optical microstructures for a high purity iron (a) and an Fe-0.05P alloy (b) interrupted after deformation to $30 \%$ strain at $773 \mathrm{~K}$.

Figure 5 shows the microstructures for a high purity iron (a) and an Fe-0.05P alloy (b) interrupted after deformation to $30 \%$ strain at $773 \mathrm{~K}$. Recrystallized grains with an average size of about $10 \mu \mathrm{m}$ can be recognized in the specimens of high purity iron and Fe-0.05P alloy. However, the morphology of recrystallized grains in high purity iron is significantly different from that in Fe-0.05P alloy. The 
recrystallized grains in Fe-0.05P alloy are similar to those statically recrystallized. The boundaries between recrystallized grains in Fe-0.05P alloy are smooth compared with those in high purity iron. The difference in recrystallized microstructure between high purity iron and Fe-0.05P alloy is more clearly observed in the specimens interrupted after deformation to $30 \%$ strain at $973 \mathrm{~K}$ as shown in Figure 6. The recrystallized grains have grown to $20 \sim 30 \mu \mathrm{m}$ at $973 \mathrm{~K}$.

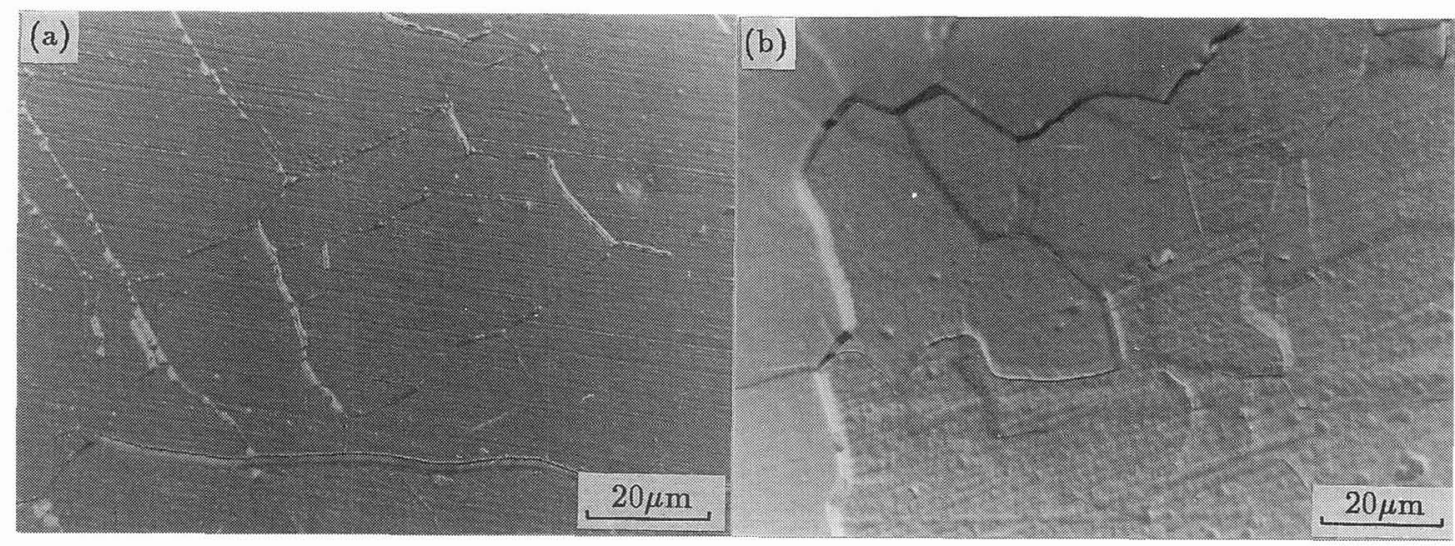

Figure 6: The optical microstructures for a high purity iron (a) and an Fe-0.05P alloy (b) interrupted after deformation to $30 \%$ strain at $973 \mathrm{~K}$.

\section{DISCUSSION}

From the present experimental results, it is clear that the significant effects of phosphorus on mechanical properties of high purity iron are the strengthening of iron below $1073 \mathrm{~K}$ and the increase in the elongation to rupture above $773 \mathrm{~K}$. The increase in proof stress by phosphorus is due to the solid solution hardening by phosphorus. This is qualitatively consistent with the results in previous research $[3,15]$. On the other hand, the effect of phosphorus on the elongation of high purity iron is essentially different from that in the previous research [3-5] in two aspects. In the present study, high purity iron shows no minimum in elongation above $723 \mathrm{~K}$, and no intergranular cavitation occurs either in high purity iron or in $\mathrm{Fe}-\mathrm{P}$ alloys at any test temperature. The effect of phosphorus in the present study seems more intrinsic.

The effect of phosphorus on hot ductility in previous research has been attributed to the suppression of intergranular cavitation by the addition of phosphorus [3-9]. However, the increase in hot ductility of high purity iron by the addition of phosphorus in the present study seems to result from the effect of phosphorus on the dynamic recrystallization of high purity iron. As shown in Figures 5 and 6, the microstructure of high purity iron dynamically recrystallized above $773 \mathrm{~K}$ is significantly different from that of $\mathrm{Fe}-0.05 \mathrm{P}$ alloy. The microstructure of high purity iron might be unfavourable to the further uniform deformation of a specimen compared with that of Fe-P alloys, although the detail of the microstructural effect on uniform deformation remains unclear at the present time.

The difference in the dynamically recrystallized microstructure between high purity iron and Fe-P alloys might be caused by the effect of phosphorus on the dynamic recovery rate of iron. As shown in Figures 3 and 4, Fe-P alloys show an increased work hardening rate and a larger number of slip lines. These experimental results suggest that the addition of phosphorus to high purity iron reduces the recovery rate. The reduction in recovery rate supplies increased driving energy for recrystallization. Although the mechanism of the reduction in the recovery rate of iron by the addition of phosphorus is not clear, the rates of climb of dislocations and the motion of jog are decreased because phosphorus interacts attractively with vacancies [16] in high purity iron. 


\section{CONCLUSIONS}

(1) The addition of phosphorus to high purity iron causes a remarkable increase in the proof stress of high purity iron at $300 \mathrm{~K}$. The increase in proof stress by phosphorus decreases with increasing test temperature. The strengthening effect of phosphorus reduces to zero at $1073 \mathrm{~K}$.

(2) High purity iron and Fe-P alloys rupture at almost $100 \%$ reduction in area at the test temperatures between $300 \mathrm{~K}$ and $1073 \mathrm{~K}$. No brittle fracture occurred.

(3) The addition of phosphorus drastically increases the elongation of iron above $773 \mathrm{~K}$ as its intrinsic effect, which results from the effect of phosphorus on dynamic recovery and recrystallization of iron.

\section{Acknowledgements}

The authors are grateful to Toho Zinc Co. Ltd. for their donation of high purity electrolytic iron. The authors are also grateful to Mr. N. Harima for preparing the high purity alloys. This work was financially supported by the Ministry of Education, Science and Culture of Japan through Grant-in-Aid for Scientific Research (B) No.05452284.

\section{References}

[1] Abiko K. and Liu C.M., Proceedings of the Robert I. Jaffee Memorial Symposium on Clean Materials Technology, ASM/TMS Materials Week, 2-5 November 1992, Chicago, Illinois, USA, pp.9-16.

[2] Abiko K., Proceedings of The First International Conference on Ultra High Purity Base Metals, Kitakyushu-City, Japan, May 24-27, 1994, K. Abiko, K. Hirokawa and S. Takaki Eds. (the Japan Institute of Metals, Sendai, Japan, 1995) pp.1-26.

[3] Kirby B.R. and Beevers C.J., Scripta Metall., 11(1977)659-663.

[4] Abiko K., Bodnar R.L. and Pope D.P., Ductility and Toughness Considerations in Elevated Temperature Service, G.V. Smith ed., (ASME, New York, 1979) pp.1-10.

[5] Wilkinson D.S., Abiko K., Thyagarajan N. and Pope D.P., Metall. Trans., 11A(1980)18271836.

[6] Takasugi T. and Pope D.P., Metall. Trans. 13A(1982)1471-1481.

[7] Takasugi T. and Pope D.P., Mater. Sci. Eng., 57(1983)15-20.

[8] Chen S.-H., Takasugi T. and Pope D.P., Metall. Trans., 14A(1983)571-580.

[9] George E.P., Chen S.-H. and Pope D.P., Scripta Metall., 20(1986)1775-1779.

[10] George E.P., Li P.L. and Pope D.P., Acta Metall., 35(1987)2471-2486.

[11] Gcorge E.P., Li P.L. and Pope D.P., Acta Metall., 35(1987)2487-2495.

[12] Li P.L., George E.P. and Pope D.P., Metall. Trans., 19A(1987)887-892.

[13] Liu C.M., Suenaga H., Abiko K. and Tanino M., Abstracts of the Japan Institute of Metals, 111(1992)111, to be published.

[14] Liu C.M., Iyama T., Suenaga H., Abiko K. and Tanino M., Proceedings of The First International Conference on Ultra High Purity Base Metals, Kitakyushu-City, Japan, May 24-27, 1994, K. Abiko, K. Hirokawa and S. Takaki Eds. (the Japan Institute of Metals, Sendai, Japan, 1995) pp.500-506.

[15] Spitzig W.A., Metall. Trans., 3(1972)1183-1188.

[16] Kawamoto A., Thesis for Doctor of Eng. Degree, Tohoku University, Sendai Japan, 1899. 